\title{
Comfort Parameters Tuning Analysis for Vehicle Suspension Pitch Performance
}

\author{
Ahmed Esmael Mohan ${ }^{\# 1}$, Mohd Azman Abdullah ${ }^{*+\$ 2}$, Muhammad Aliff Isyraq Azmi ${ }^{+3}$, Ariffirdaus \\ Arsaat $^{+4}$, Wan Mohd Zailimi Wan Abdullah ${ }^{*+5}$, Mohd Hanif Harun ${ }^{*+6}$, and Fauzi Ahmad ${ }^{*+7}$ \\ \# Al-Mussaib Technical College/Al-Furat Al-Awsat Technical University \\ 51009, Babylon, Iraq \\ 1ahmedalshebawy@gmail.com \\ ${ }^{*}$ Centre for Advanced Research on Energy, Universiti Teknikal Malaysia Melaka (UTeM), \\ Hang Tuah Jaya, 76100 Durian Tunggal, Melaka, Malaysia \\ 2․mohdazman@utem.edu.my, ${ }^{5}$ zailimi@utem.edu.my, ${ }^{6}$ hanif@utem.edu.my, ${ }^{7}$ fauzi.ahmad@utem.edu.my \\ ${ }^{+}$Faculty of Mechanical Engineering, Universiti Teknikal Malaysia Melaka, \\ Hang Tuah Jaya, 76100 Durian Tunggal, Melaka, Malaysia \\ ${ }^{3}$ muhammad.aliff@utem.edu.my, ${ }^{4}$ ariffirdaus@utem.edu.my \\ \$Rolling Stock Department (RST), ERL Maintenance Support Sdn. Bhd. (E-MAS) (498574-T), \\ Kompleks Rel Udara, Bandar Baru Salak Tinggi, 43900 Sepang, Selangor, Malaysia
}

\begin{abstract}
Suspension system is the mechanism that is applied between the tire and the body of a vehicle. It absorbs the undesirable force that exerted on the tire transmitted to the body of the vehicle. In order to reduce the undesirable force from uneven road, the spring stiffness and damping value of the suspension should be tuned to improve the passengers' comfort. The suspension is tuned at various values of spring stiffness and damping that initially verified from a commercial vehicle dynamic software. The tuning process considers the vertical and pitch performances of the vehicle through a simple step inputs. From the analysis, the values of overshoot for vertical and pitch motions are compared. The lower the values the better the performance of the tuned parameters. A sport utility vehicle (SUV) is used for this tuning analysis. The optimal values of spring stiffness and damping are determined and can be used for further dynamic control and comfort improvement study.
\end{abstract}

Keyword-Passive suspension, parameters tuning, vehicle comfort, vehicle pitch, vehicle dynamic

\section{INTRODUCTION}

Suspension system is one of the most important and basic system in a vehicle. The purpose of suspension system is to isolate the vehicle from disturbances that can help driver can keep control of the vehicle and to protect the passenger from feel the shaking when they drive across the road with bump or hole or even on the smooth road. The suspension also helps to support the vehicle weight, improve the stability of vehicles and maintain the correct vehicle ride motion [1,2]. There are main criteria to improve the comfort parameter the vehicle suspension system which are vibration isolation on the vehicle body, suspension travel between vehicle body with the wheel and road holding between the tires with road surface. Numerous studies have been conducted on the suspension system in order to minimize the vertical motion, as well as pitch and roll movements, as the vehicle passes over an irregular road, performs turning manoeuvres, and is accelerated or brakes heavily and to achieve the stability and ride comfort in the vehicle [3, 4].

Pitch and bounce vibration modes are as far as the ride is concerned. Basically, a pitch motion is an upward and downward movement of the front and rear of vehicle body. A pitch motion of vehicle is rotating on $y$-axis or lateral of the vehicle body through its centre of gravity and parallel to the air flow. In order to improve the ride comfort, the damping coefficient and the spring stiffness should be an optimal value. The optimal value of damping coefficient and spring stiffness will minimize the transmissibility of vibration from the rough surface that acting on the vehicles body. Furthermore, the ride natural frequency also will affect the pitch motion of the vehicles in order to reduce the resonant peak of the suspension. The higher the ride natural frequency will minimize the transmissibility of vibration. Ride frequency for front body and rear body are generally not same. The rear body needs higher natural frequency to catch up the front body to reduce the pitch motion [5-8].

In order to achieve the ride comfort for the vehicle, it need to find the suitable spring stiffness and the damping coefficient for ride dynamic of the vehicles. From the simulation process, it will produce line graph that need to simulate the different effect of vibration isolation when varied the value of spring stiffness and damping coefficient. The result from Matlab Simulink software need to transfer in CarSim software to analyse 
the real motion of the passenger vehicle with different effect of real situation. The suspension will be test in the CarSim software with varies input parameter tuning until achieve the ride comfort of the passenger vehicles.

Ride comfort is defined as the overall comfort including of the passenger during travel which is also known as ride quality. Suspension of the vehicle is the main factor to increase the ride comfort for passenger and vehicle. When the vehicle travel through unevenness road surface, the vehicle body will produce vibration isolation effect. The vibration isolation of the vehicle should be reducing in order to improve the ride comfort for passenger and vehicle. There are several steps to reduce the vibration which are improved the quality of the road condition, select suitable type of tyre for the vehicle and tuning the suspension with optimal parameter. It is because there are plays an important factor as an elastic components and damping element to absorb the vibration energy. Moreover, the elastic components also can buffer the impact, reduce vibration and transmit force respectively. It is known as the soul of chassis design which is an important component to ensure ride comfort and handling stability $[9,10]$.

The rigidity and damping parameter of the suspension system are selected through empirical design or optimization method. Since the vehicle ride comfort and handling stability are contradicting the suspension system, a compromise must be made to fulfil the requirement of both performances. The parameters of its suspension characteristic cannot be adjusted to the vehicle's operational states and incentive changes. Hence, the further improvement of its vibration reduction performance is restrained. In order to get an optimal damping parameter for suspension system, it need to observe the vertical displacement of vehicle body, road input and ratio of wheel to indicate the comfort level for the passenger. A damping coefficient of $1000 \mathrm{Ns} / \mathrm{m}$ will produce the lowest transmissibility which are vibration isolation, suspension travel and road holding [11, 12].

In a vehicle system modelling, the vehicle dynamic behaviour can be determined when the forces exerting to the vehicle from the tires, gravity and aerodynamics. All of the movement will be effect on the comfort of vehicles. In order to achieve vehicle comfort, many aspects should consider such as the translational motion and moments of the vehicle system. Basically, a vehicle system consists of three translational motions and three moments which are the longitudinal motion through $\mathrm{x}$-axis where the direction to the front of the vehicle is positive value, the lateral motion through the $y$-axis where the direction to the right side of the vehicle is the positive value, the vertical motion through z-axis where the upward direction is positive value, the roll moment about the $\mathrm{x}$-axis where clockwise direction is positive, the pitch moment about the $\mathrm{y}$-axis where clockwise is positive and the yaw moment about the z-axis where clockwise direction is positive [13-16].

Most of the vehicle has a problem among the comfort of the vehicle when through the unevenness road. The vehicle will stimulate a harmonic response in the pitch mode due to road disturbance. Pitch motion of the vehicle will occur more rapidly compare to the heave motion in response to the vertical disturbances. Pitch motion and heave motion are related linked through the concept of "centres of oscillation". The centres of oscillation may be determined by solving the Eigenvectors of two degree of freedom "Bounce-Pitch Model". The interaction between pitch motion and heave motion may be examining the heave-pitch coupling term in the total stiffness matrix. Actually, pure pitch motion does not only effect the load transfer across on one axle but the load transfer will be support by both axle of the vehicle. This is because of rotational acceleration about the $y$-axis, through this effect is generally very small owing to the small pitch angles and low rotational acceleration. Mostly, the load transfer situation may be occur during the vehicle braking, accelerate or through unevenness road surface. When these situation happen, the pitch acceleration may be large, but in response to vertical disturbances this effect is likely to be small. The recovery of that pitch condition back to ride height results in weight transfer due to pitch $[17,18]$.

In this study, a 4DOF half car pitch plane ride model [19] that allowed the vehicle body to move in vertical and pitch direction and each wheel is allowed to move in vertical direction. Basically, in the pitch movement of vehicle body, the suspension system will produce a ride comfort rate and natural frequency. In order to improve the ride comfort of the vehicle, it need to reduce the vibration isolation on the suspension. The best vibration isolation will be achieved by keeping the natural frequency as low as possible. The lower the vibration isolation between the vehicle body vertical displacement response and road input, it will form a better performance on the suspension system for the vehicle. The suspension parameters of spring stiffness and damping are tuned based on original values. Simulation of the vehicle is performed at different tuned parameters. The performances of the vehicles in term of vertical vibration and pitch moment are analysed and compared to determine the comfortless of the vehicles.

\section{MEthodology}

Previously verified 4DOF vehicle model (Fig. 1) $[19,20]$ is used for comparison with simulation software. In this research, the vehicle will be interpreted in a 4DOF pitch plane model. The model will be in X-z plane of the vehicle which is the side view of the vehicle with inputs of road disturbance $z_{r r}$ and/or $z_{r}$. The initial parameters of the vehicle is taken from commercial vehicle dynamic software CarSim (TABLE I). The spring stiffness $k_{s f}$ and $k_{s r}$ are tuned at different values as follows; $k_{1}=130 \mathrm{kN} / \mathrm{m}, k_{2}=153 \mathrm{kN} / \mathrm{m}, k_{3}=189 \mathrm{kN} / \mathrm{m}, k_{4}=200 \mathrm{kN} / \mathrm{m}$ and $k_{5}=230 \mathrm{kN} / \mathrm{m}$. While for damping value $c_{s f}$ and $c_{s r}$ are tuned at different values as follows; $c_{1}=10 \mathrm{kNs} / \mathrm{m}$, 
$c_{2}=20 \mathrm{kNs} / \mathrm{m}, c_{3}=30 \mathrm{kNs} / \mathrm{m}, c_{4}=40 \mathrm{kNs} / \mathrm{m}$ and $c_{5}=50 \mathrm{kNs} / \mathrm{m}$. Fig. 2 shows the SUV model from CarSim software. Fig. 3 shows step input for the 4DOF pitch model of the SUV.

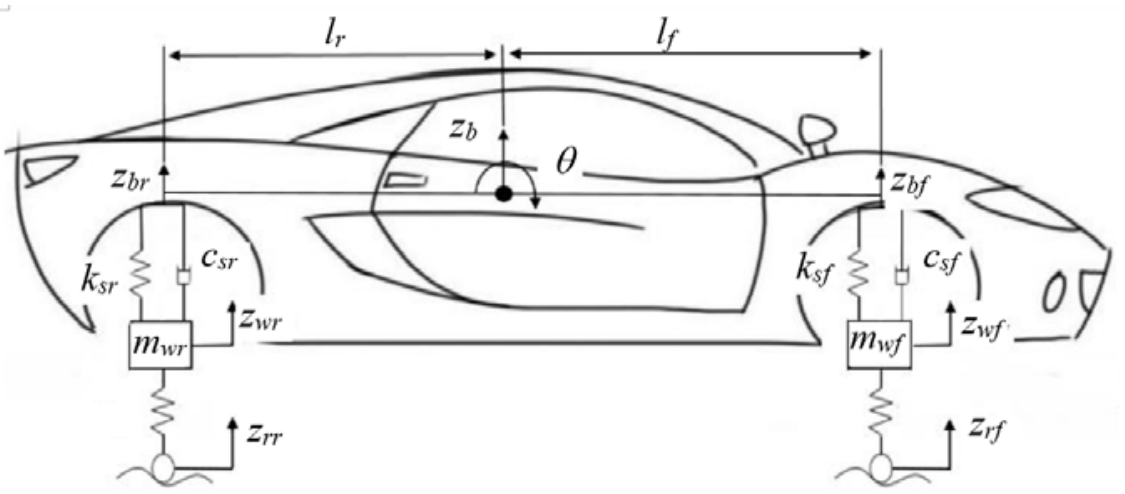

Fig. 1. 4DOF half-car pitch plane ride model

TABLE I

Initial parameters of SUV

\begin{tabular}{|l|l|l|}
\hline Parameter & Value & Unit \\
\hline Vehicle body mass, $m_{b}$ & 2257 & $\mathrm{~kg}$ \\
\hline Distance between CG and front axle, $l_{f}$ & 1.33 & $\mathrm{~m}$ \\
\hline Distance between CG and rear axle, $l_{r}$ & 1.62 & $\mathrm{~m}$ \\
\hline Pitch inertia, $I_{\theta}$ & 3524.9 & $\mathrm{~kg} / \mathrm{m}^{2}$ \\
\hline Front suspension spring stiffness, $k_{s f}$ & 189000 & $\mathrm{~N} / \mathrm{m}$ \\
\hline Rear suspension spring stiffness, $k_{s r}$ & 189000 & $\mathrm{~N} / \mathrm{m}$ \\
\hline Front suspension damping, $c_{s f}$ & 30000 & $\mathrm{Ns} / \mathrm{m}$ \\
\hline Rear suspension damping, $c_{s r}$ & 30000 & $\mathrm{Ns} / \mathrm{m}$ \\
\hline Front tire stiffness, $k_{t f}$ & 250000 & $\mathrm{~N} / \mathrm{m}$ \\
\hline Rear tire stiffness, $k_{t r}$ & 250000 & $\mathrm{~N} / \mathrm{m}$ \\
\hline Front wheel mass, $m_{w f}$ & 125 & $\mathrm{~kg}$ \\
\hline Rear wheel mass, $m_{w r}$ & 150 & $\mathrm{~kg}$ \\
\hline
\end{tabular}

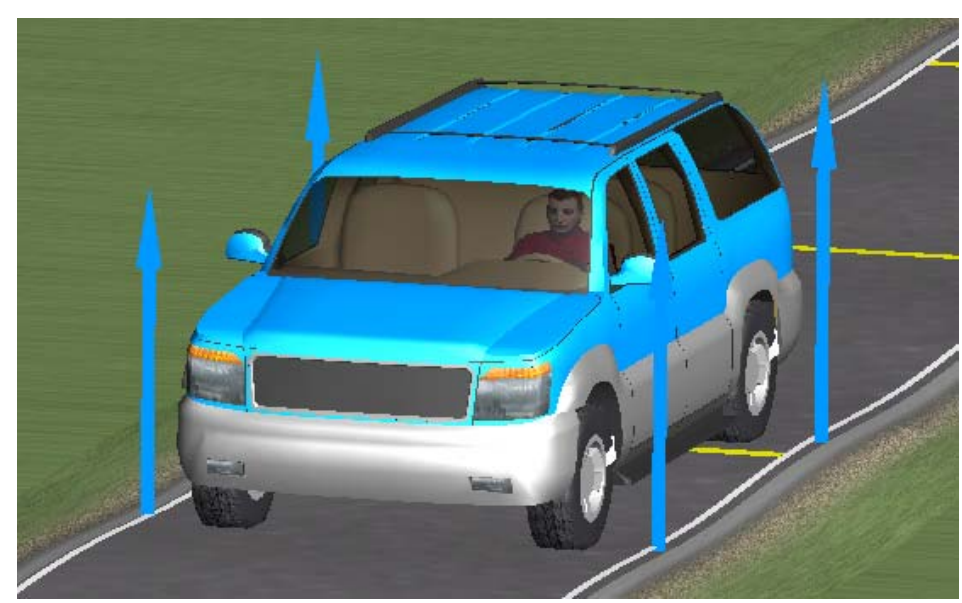

Fig. 2. SUV model from CarSim

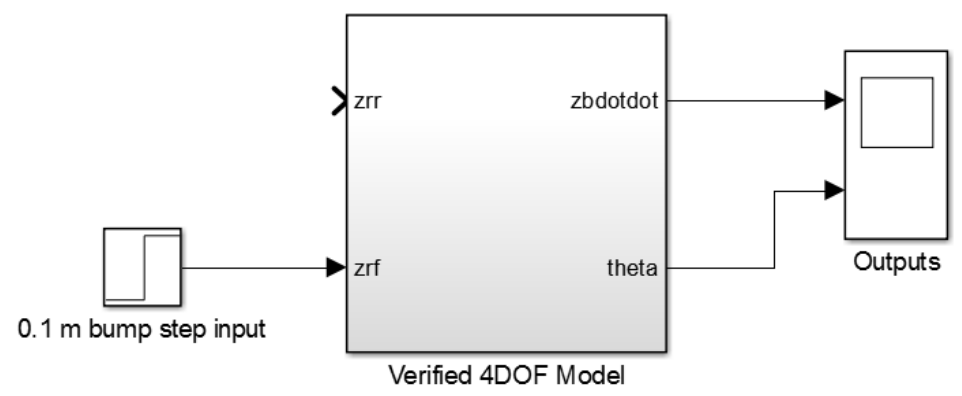

Fig. 3. Step input $(0.1 \mathrm{~m})$ for the $4 \mathrm{DOF}$ pitch model in Matlab 


\section{RESULTS AND DISCUSSION}

Fig. 4 until Fig. 8 show the results of pitch body effect with five constant values of spring stiffness on five different values of damping. When the vehicle hit the bump $0.1 \mathrm{~m}$ on the road surface, it will produce a result of amplitude overshoot and settling time with various pattern depending on parameters of vehicle, spring stiffness and damping value. In this study, only overshoot is analysed for the comfort performance since it affects the instant response of the suspension.

Based on figures below, it can be observed that the overshoot of the pitch body affected by each value of spring stiffness and damping value. For example in Fig. 4(b), the value of overshoot at $c_{5}=50 \mathrm{kNs} / \mathrm{m}$ is 3.48 degree. So, the lower the value of damping the lower the value of the overshoot pitch. It can be noted that when no damping is provided the amplitude of overshoot is increased with time which means passenger will be getting lots of vibration and also it can damage the vehicle with a lot of wear and tear in the system. The highest the value of damping will provide the vehicle more comfort during driving through an uneven road. So, to improve the comfort of the vehicle, it need to select the optimal spring stiffness and damping value that suitable with the SUV.

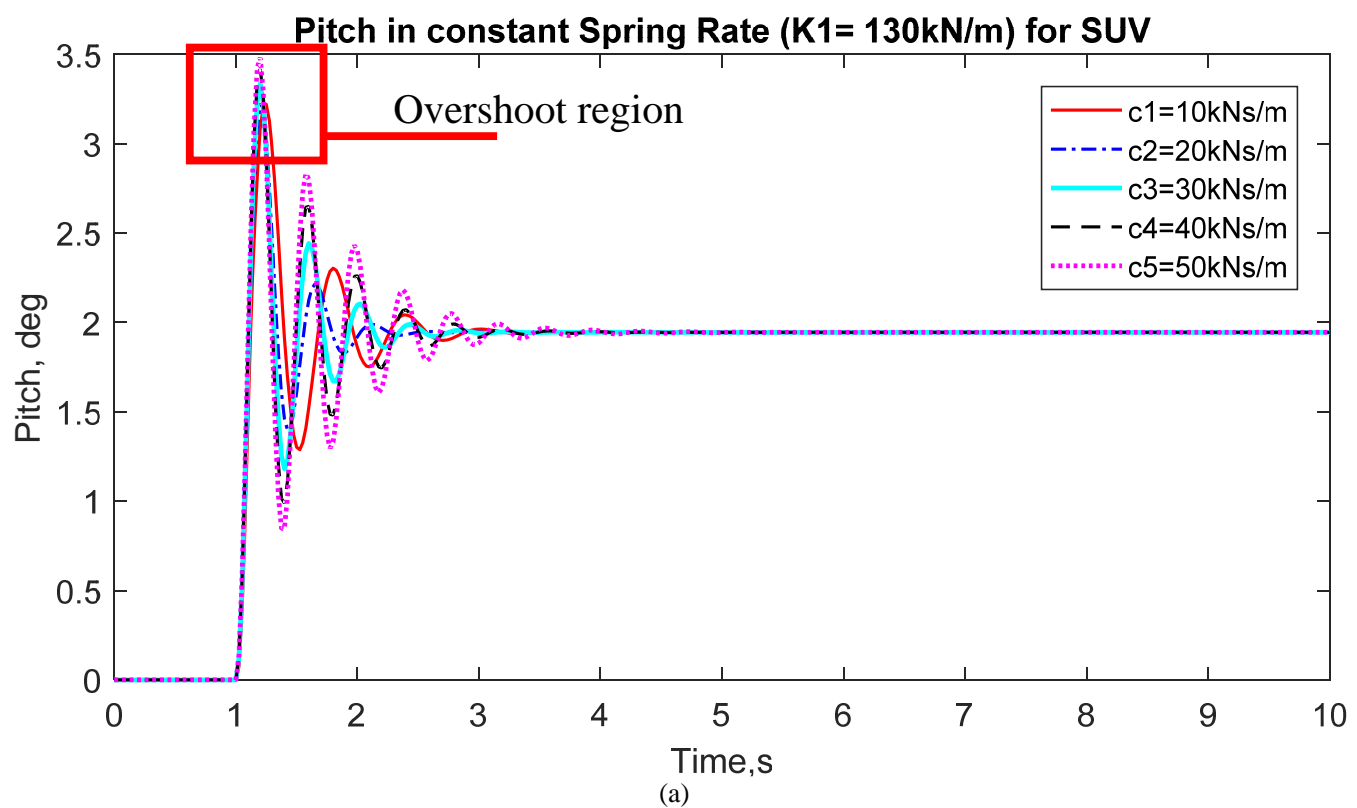

(a)

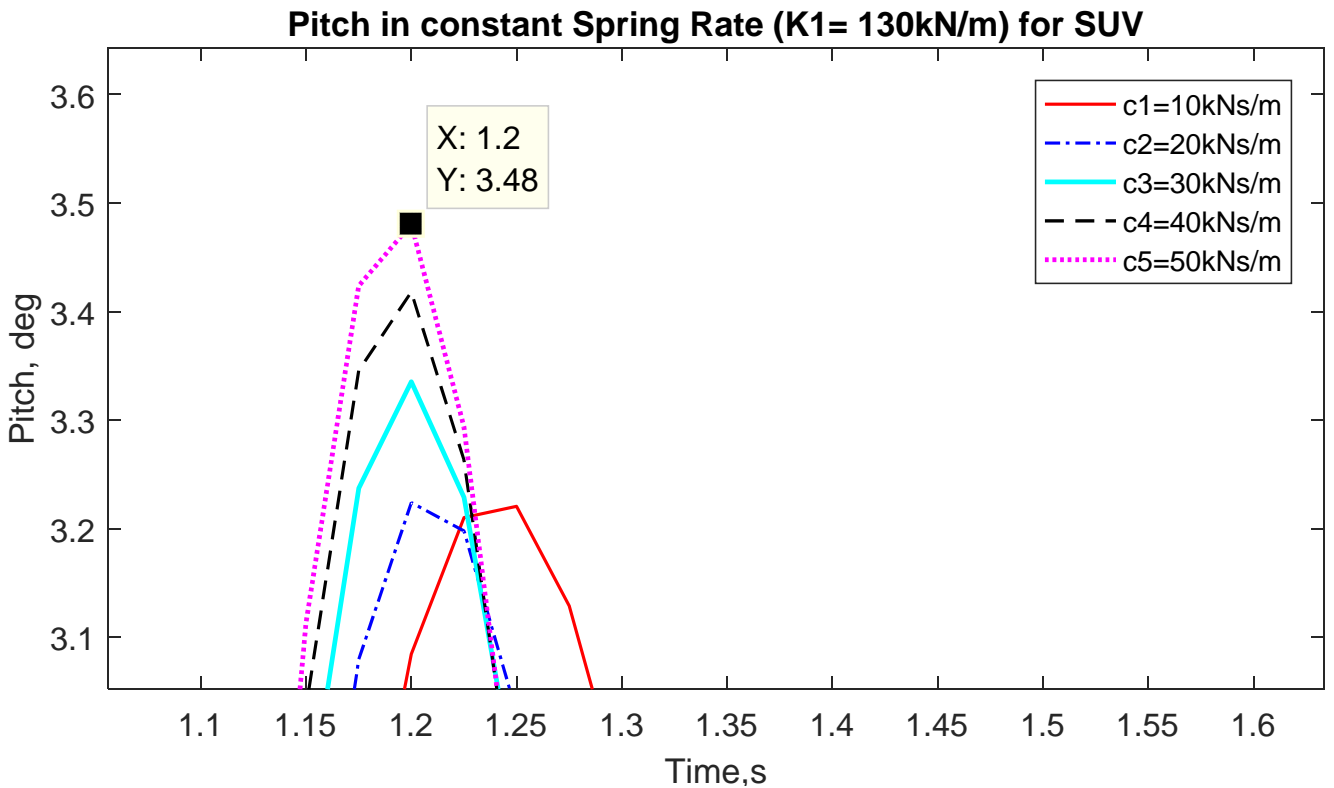

(b)

Fig. 4. Pitch at constant spring rate $\left(k_{1}=130 \mathrm{kN} / \mathrm{m}\right)$ for SUV (a) Overall results, (b) Overshoot region enlarged 


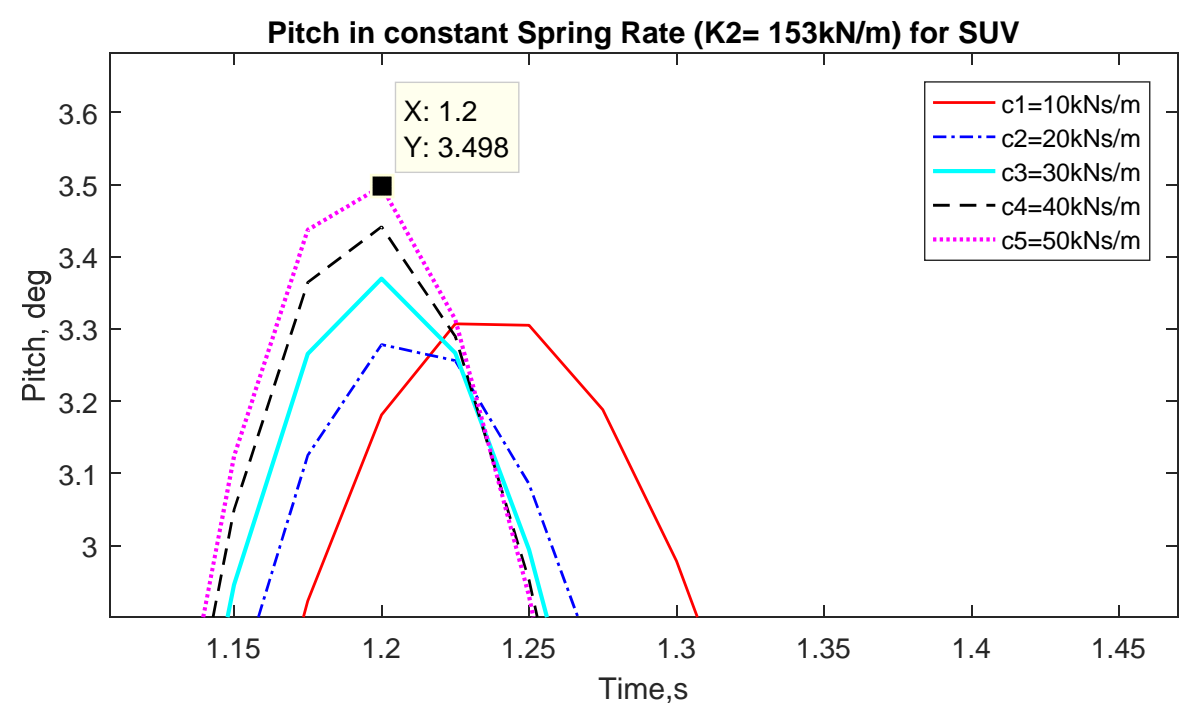

Fig. 5. Pitch at constant spring rate $\left(k_{2}=153 \mathrm{kN} / \mathrm{m}\right)$ for SUV at overshoot region

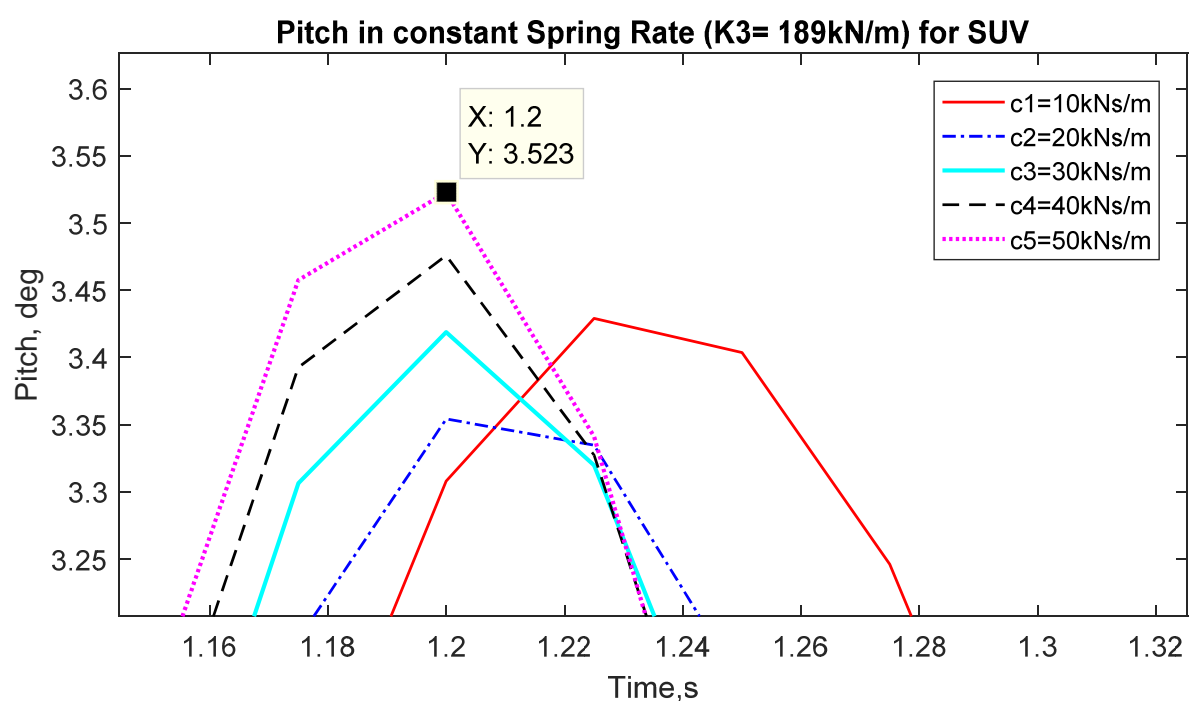

Fig. 6. Pitch at constant spring rate $\left(k_{3}=189 \mathrm{kN} / \mathrm{m}\right)$ for SUV at overshoot region

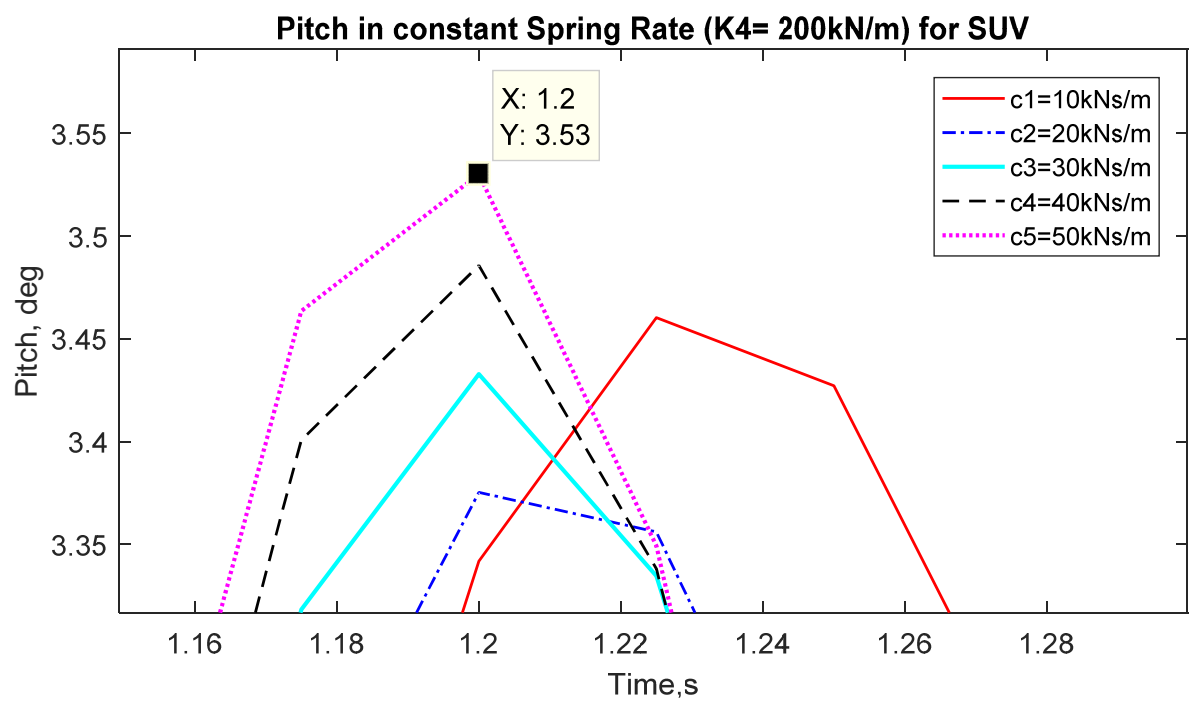

Fig. 7. Pitch at constant spring rate $\left(k_{4}=200 \mathrm{kN} / \mathrm{m}\right)$ for SUV at overshoot region 


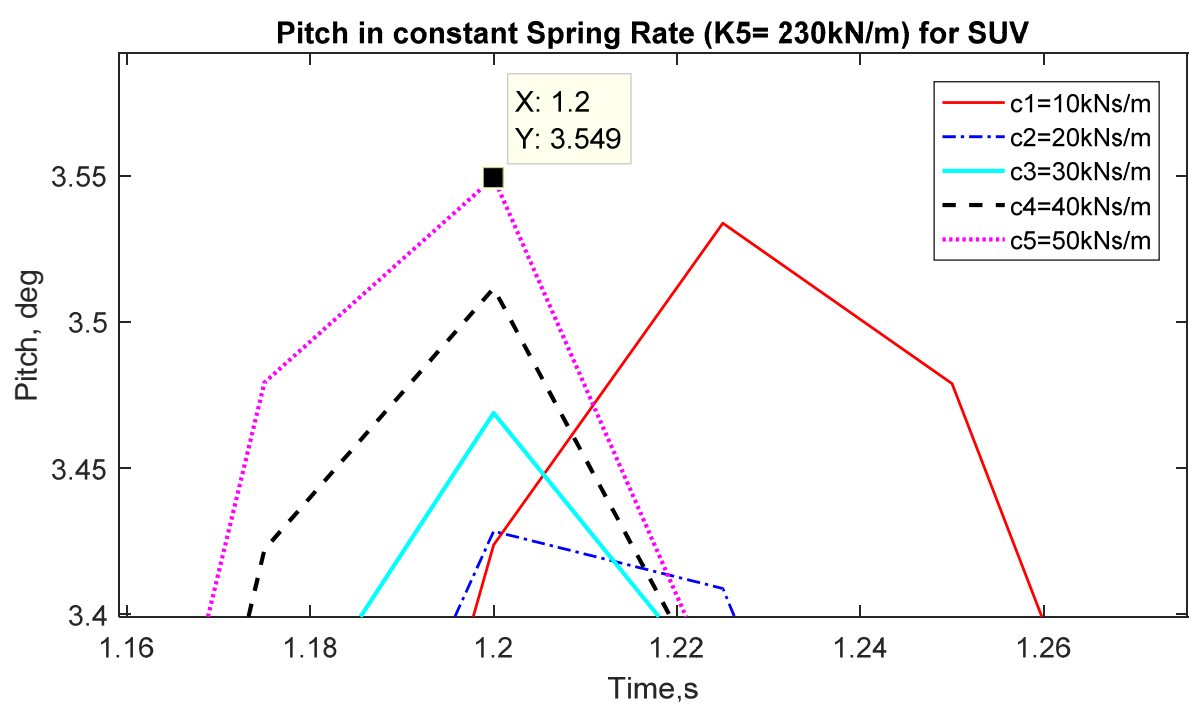

Fig. 8. Pitch at constant spring rate $\left(k_{5}=230 \mathrm{kN} / \mathrm{m}\right)$ for SUV at overshoot region

TABLE II summarizes the overshoot pitch value of the SUV at different spring stiffness and damping. Fig. 9 shows the overall results for SUV in graphical form. It can be noted that the different spring stiffness and damping value the performance of the vehicle suspension system. Basically, the spring stiffness and damping value of suspension system will be selected depending on the vehicle parameter. If the vehicle has a heavy mass on the vehicle body, the spring stiffness and damping value should be higher to support the vertical motion of the vehicle body when hit a bump or driving through an uneven road. It is because suspension spring able to support the weight of vehicle body and passenger while a damper able to absorb and reduce the bounce force that exerted on the vehicle body. From overall simulation result for SUV, it can be noted that damping value is more important in vehicle compare to spring stiffness. It is because the damper will absorb the vertical force that affect the pitch motion on the vehicle body and reduce the bounce force from the road surface transmit to vehicle body while the spring of suspension only hold the vehicle body from the shock impact. So, in order to achieve the comfort of the vehicle, it need to select the optimal value of spring stiffness and damping which are suitable with the parameter of the SUV. From the figure, it can be observed that at lower values of damping and spring stiffness, the suspension produce the lowest overshoot.

TABLE II

Overshoot (pitch, deg) for SUV

\begin{tabular}{|l|c|c|c|c|c|}
\hline \multirow{2}{*}{ Spring stiffness, kN/m } & \multicolumn{5}{|c|}{ Damping value, kNs/m } \\
\cline { 2 - 6 } & $c_{1}=10$ & \multicolumn{5}{|c|}{$c_{2}=20$} & \multicolumn{5}{|c|}{$c_{3}=30$} & $c_{4}=40$ & $c_{5}=50$ \\
\cline { 2 - 6 } & \multicolumn{5}{|c|}{ Overshoot, degree } \\
\hline$k_{1}=130$ & 3.221 & 3.224 & 3.335 & 3.418 & 3.480 \\
\hline$k_{2}=153$ & 3.307 & 3.278 & 3.370 & 3.442 & 3.498 \\
\hline$k_{3}=189$ & 3.429 & 3.354 & 3.419 & 3.476 & 3.523 \\
\hline$k_{4}=200$ & 3.460 & 3.375 & 3.433 & 3.486 & 3.530 \\
\hline$k_{5}=230$ & 3.534 & 3.428 & 3.469 & 3.511 & 3.549 \\
\hline
\end{tabular}

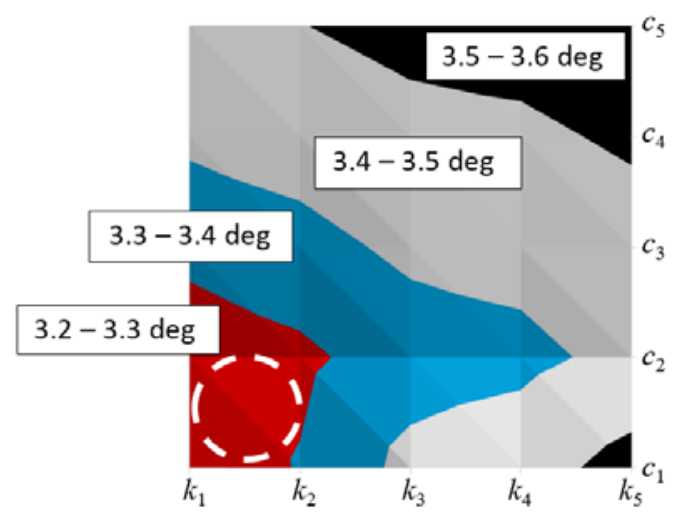

Fig. 9. Overshoot (pitch, deg) for SUV 
Fig. 10 until Fig. 14 show that the result of vertical acceleration overshoot of the SUV at different value of spring stiffness and damping. It can be observed the effect of vertical body acceleration based on the fivedifferent value of damping with constant spring stiffness on the SUV. For example, the vertical vibration overshoot is $8.456 \mathrm{~m} / \mathrm{s}^{2}$ for damping value $c_{5}=50 \mathrm{kNs} / \mathrm{m}$ and spring stiffness $k_{1}=130 \mathrm{kN} / \mathrm{m}$ (Fig. 10(b)). Damper is the important component of the suspension system to absorb the undesirable force from the road exerted on the vehicle body. So, in order to improve the comfort of SUV, it is needed to determine the optimal damping value that are able to reduce the overshoot value of vertical body acceleration. It can be noted that from the simulation, the higher the value of damping on the SUV, the lower the overshoot of the vertical body acceleration. TABLE III summarizes the values of overshoot that experienced on vertical body acceleration with various spring stiffness and damping. It can see that the lowest overshoot value that experienced on vertical body acceleration on the SUV is at spring stiffness about $130 \mathrm{kN} / \mathrm{s}$ and damping value about $10 \mathrm{kNs} / \mathrm{m}$. Fig. 15 shows the distribution of vertical vibration overshoot at different damping and stiffness. It can be observed that the lowest value of overshoot is at the range of $c_{1}$ and $k_{1}$.

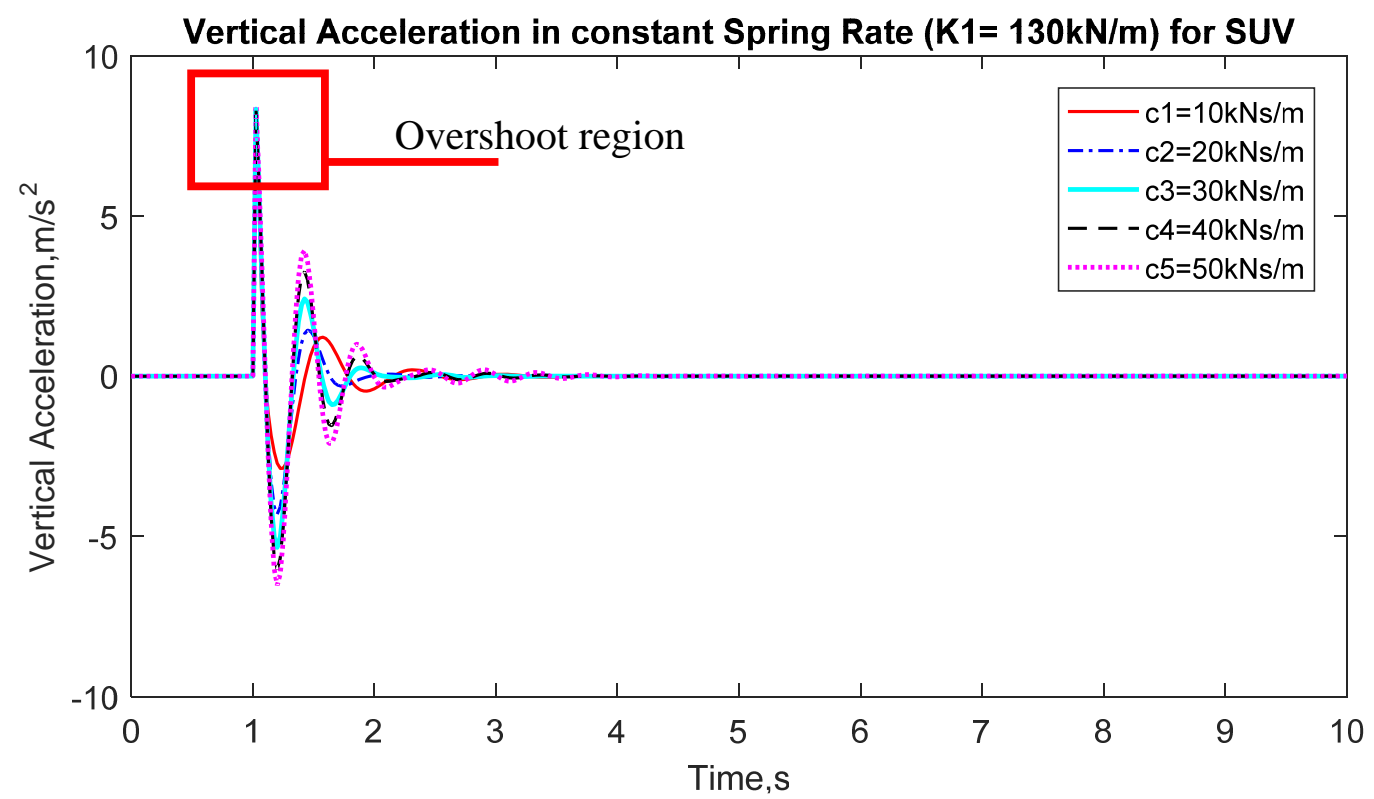

(a)

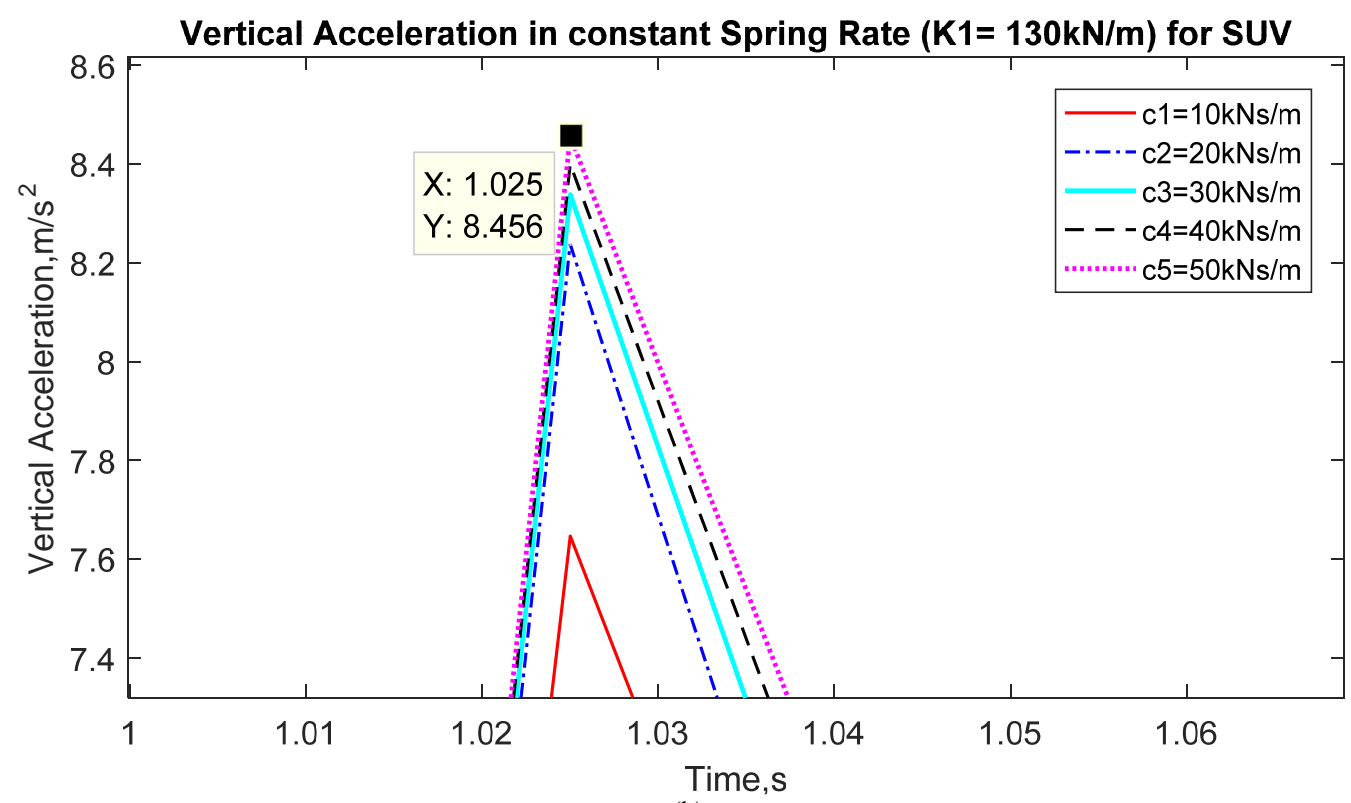

(b)

Fig. 10. Vertical acceleration at constant spring rate $\left(k_{1}=130 \mathrm{kN} / \mathrm{m}\right)$ for SUV (a) Overall results, (b) Overshoot region enlarged 


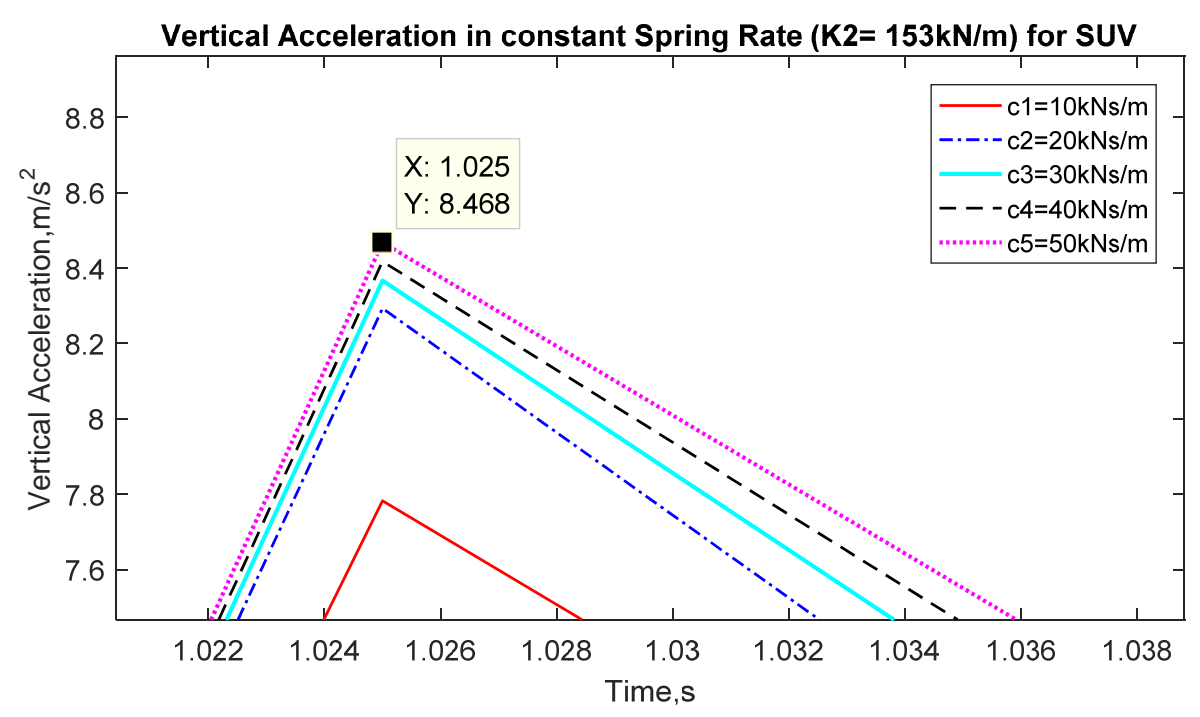

Fig. 11. Vertical acceleration at constant spring rate $\left(k_{2}=153 \mathrm{kN} / \mathrm{m}\right)$ for SUV at overshoot region

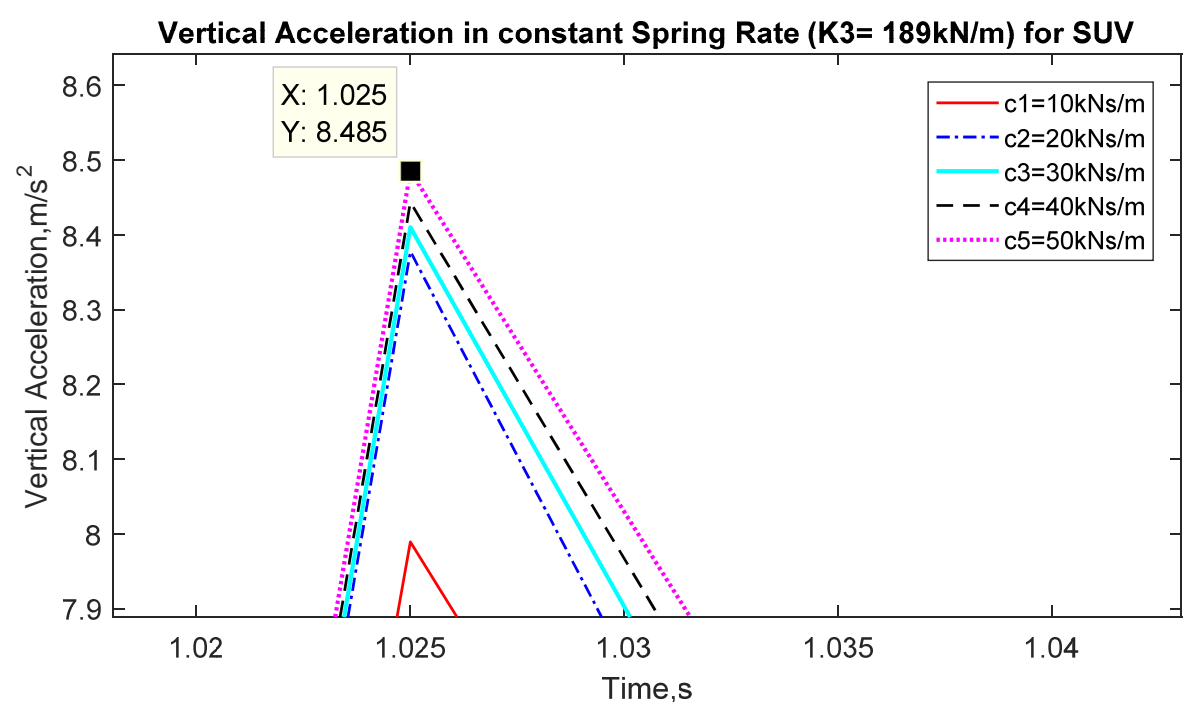

Fig. 12. Vertical acceleration at constant spring rate $\left(k_{3}=189 \mathrm{kN} / \mathrm{m}\right)$ for SUV at overshoot region

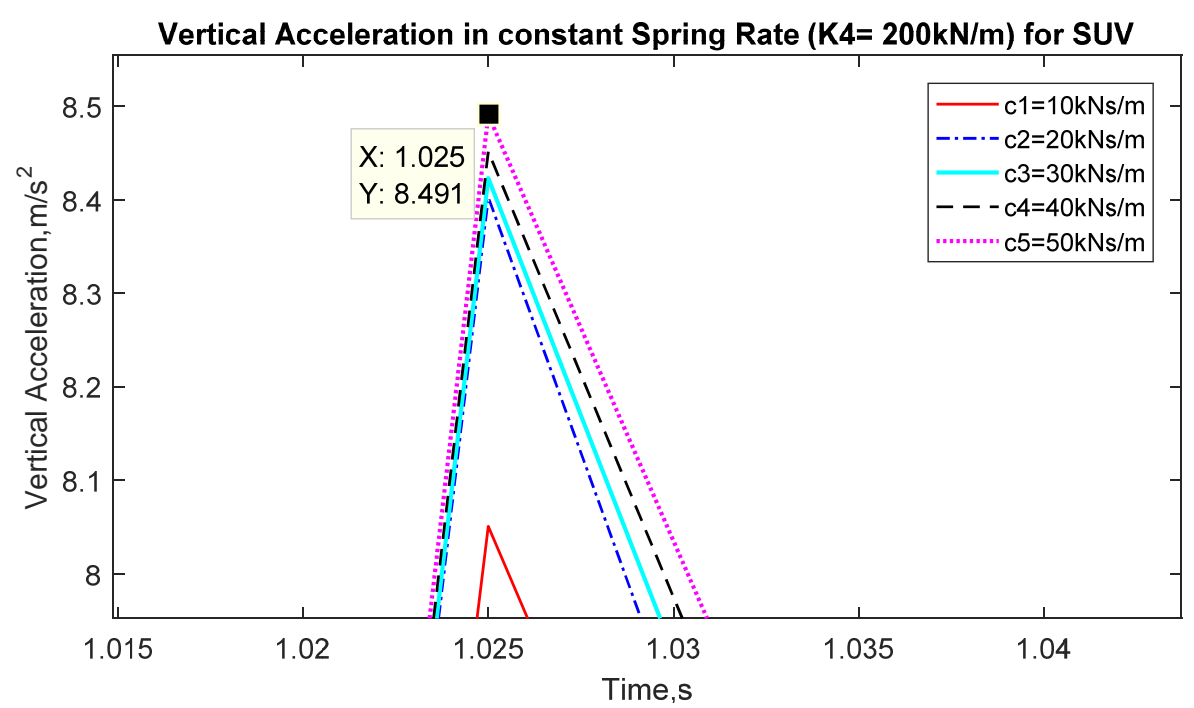

Fig. 13. Vertical acceleration at constant spring rate $\left(k_{4}=200 \mathrm{kN} / \mathrm{m}\right)$ for SUV at overshoot region 


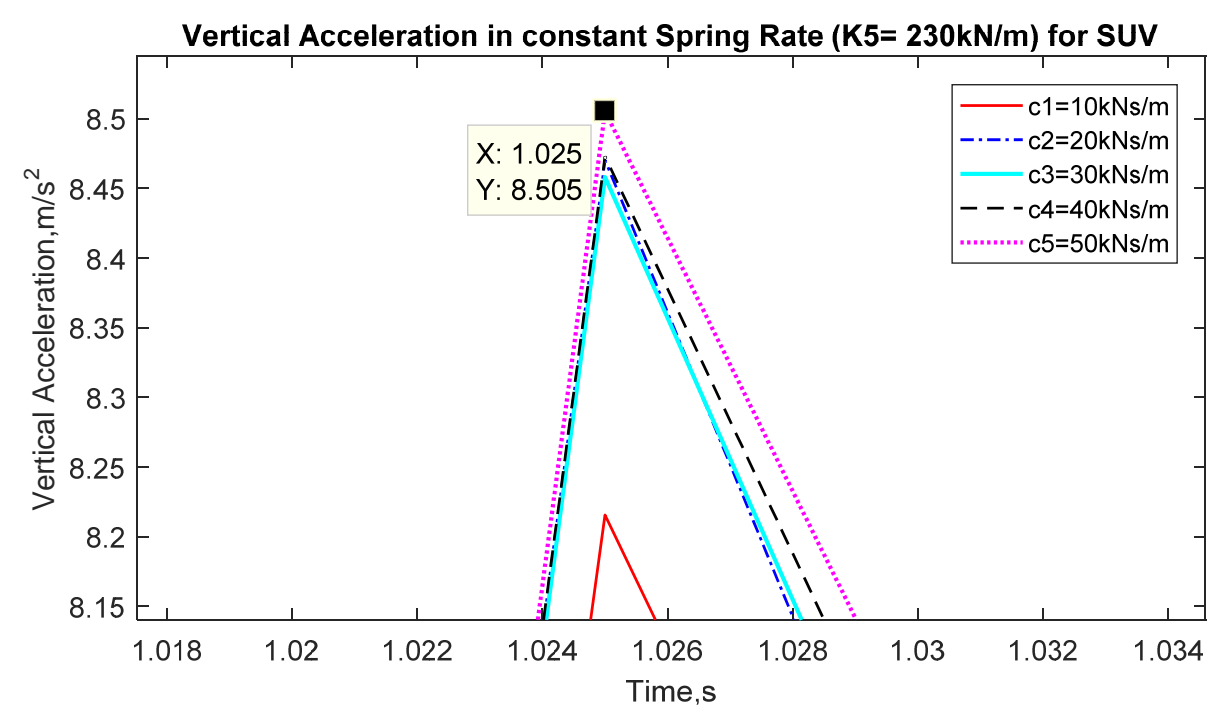

Fig. 14. Vertical acceleration at constant spring rate $\left(k_{5}=230 \mathrm{kN} / \mathrm{m}\right)$ for SUV at overshoot region

TABLE III

Overshoot (vertical acceleration, $\mathrm{m} / \mathrm{s}^{2}$ ) for SUV

\begin{tabular}{|l|c|c|c|c|c|}
\hline \multirow{3}{*}{ Spring stiffness, kN/m } & \multicolumn{5}{|c|}{ Damping value, kNs/m } \\
\cline { 2 - 6 } & $c_{1}=10$ & $c_{2}=20$ & \multicolumn{5}{|c|}{$c_{3}=30$} & $c_{4}=40$ & $c_{5}=50$ \\
\cline { 2 - 6 } & \multicolumn{5}{|c|}{ Overshoot, $\mathbf{m} / \mathbf{s}^{\mathbf{2}}$} \\
\hline$k_{1}=130$ & 7.467 & 8.470 & 8.338 & 8.400 & 8.456 \\
\hline$k_{2}=153$ & 7.783 & 8.403 & 8.367 & 8.417 & 8.468 \\
\hline$k_{3}=189$ & 7.989 & 8.378 & 8.410 & 8.444 & 8.485 \\
\hline$k_{4}=200$ & 8.051 & 8.293 & 8.423 & 8.452 & 8.491 \\
\hline$k_{5}=230$ & 8.216 & 8.238 & 8.458 & 8.473 & 8.505 \\
\hline
\end{tabular}

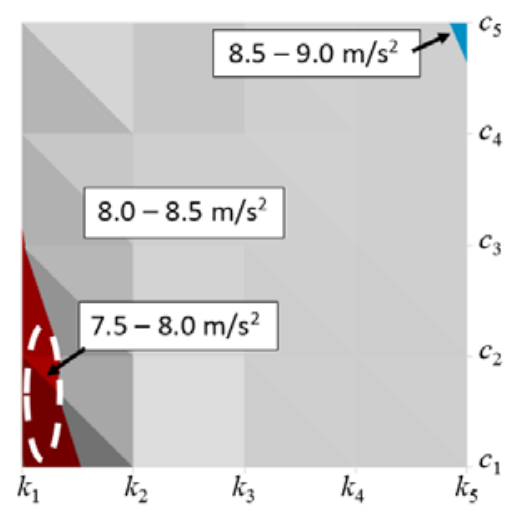

Fig. 15. Overshoot (vertical acceleration, $\mathrm{m} / \mathrm{s} 2$ ) for SUV

\section{CONCLUSION}

Pitch motion of the vehicle body represents the motion the vehicle between front body and rear body. In this study, a 4DOF pitch plane half car ride model is used to simulate the performance of a SUV at a $0.1 \mathrm{~m}$ step input. The performance of the vehicle is determined through overshoot responses of the pitch and vertical vibration at different spring stiffness's and damping values. Since smaller value of overshoot is considered as good in term of suspension response, the tuned parameters for both pitch and vertical vibration performance is in the range of 130 to $153 \mathrm{kN} / \mathrm{m}$ and 10 to $20 \mathrm{kNs} / \mathrm{m}$. These values can be used later for actual vehicle tuning and comfort performance. 


\section{ACKNOWLEDGMENT}

The authors gratefully acknowledged the support from Al-Mussaib Technical College/Al-Furat Al-Awsat Technical University and Ministry of Higher Education and Scientific Research, Iraq, Advanced Vehicle Technology (AcTiVe) research group of Centre for Advanced Research on Energy (CARe), Universiti Teknikal Malaysia Melaka and The Ministry of Education, Malaysia.

\section{REFERENCES}

[1] T.D. Gillespie, Vehicle Dynamics, Warren dale, 1997.

[2] H. Pacejka, Tire and Vehicle Dynamics, Elsevier, 2005.

[3] R. Rajamani, Vehicle Dynamics and Control, Springer Science \& Business Media, 2011.

[4] R. V. Dukkipati, J. Pang, M. S. Qatu, G. Sheng and Z. Shuguang, Road Vehicle Dynamics, SAE Technical Paper, vol. $366,2008$.

[5] M. A. Abdullah, J. F. Jamil and A. E. Mohan, Vehicle Dynamics Modeling \& Simulation, Centre for Advanced Research on Energy (CARe), Faculty of Mechanical Engineering, Universiti Teknikal Malaysia Melaka, Malacca, ISBN 978-967-0257-78-5, 2016.

[6] M. A. Abdullah, J. F. Jamil, A. E. Mohan, A. K. Mat Yamin and N. Tamaldin, Vehicle Dynamics Analysis \& Experimentation, Teaching and Learning Series, Faculty of Mechanical Engineering, Module 13, Penerbit Universiti, Universiti Teknikal Malaysia Melaka, 2016.

[7] M. A. Abdullah, J. F. Jamil, A. K. Mat Yamin, N. R. Mat Nuri and M. Z. Hassan, Vehicle Dynamics, Teaching and Learning Series, Faculty of Mechanical Engineering, Module 10, Penerbit Universiti, Universiti Teknikal Malaysia Melaka, 2015.

[8] M. A. Abdullah, J. F. Jamil and M. A. Salim, Dynamic Performances Analysis of a Real Vehicle Driving, IOP Conference Series: Materials Science and Engineering, doi:10.1088/1757-899X/100/1/012018, 2015, 100, 012017.

[9] M. A. Abdullah, M. A., Salim, M. Z. Mohammad Nasir, M. N. Sudin and F. R. Ramli, Dynamics Performances of Malaysian Passenger Vehicle, ARPN Journal of Engineering and Applied Sciences, ISSN 1819-6608, 2015, 10, 17, 7759-7763.

[10] M. A. Abdullah and M. A. H. Abdul Rahim, Driving Behaviour Analysis of Young Vehicle Drivers, Proceedings of Mechanical Engineering Research Day 2016, 2016, 19-20.

[11] M. Rosenberger, M. Plöchl, K. Six and J. Edelmann, The Dynamics of Vehicles on Roads and Tracks, Proceedings of the 24th Symposium of the International Association for Vehicle System Dynamics (IAVSD 2015), Graz, Austria, 17-21 August 2015, Crc Press, 2016.

[12] R. G. Longoria, Introduction to Vehicle System Dynamics \& Controls, 2016.

[13] M. Ibrahim, M. A. Abdullah, F. Mohamed Jamil, M. H. Harun and F. Ahmad, Analysis of Commercial Vehicle Ride Dynamics, Proceedings of Innovative Research and Industrial Dialogue 16, 2017, 181-182.

[14] F. Mohamed Jamil, M. A. Abdullah, M. R. Ridzuan, M. Ibrahim and F. Ahmad, Multi-order PID Control for a Simple Suspension System, Proceedings of Innovative Research and Industrial Dialogue 16, 2017, 143-144

[15] M. A. Abdullah, M. R. Ridzuan, F. Ahmad, F. Mohamed Jamil and M. Ibrahim, Vehicle Active Suspension Control using Multi-order PID Approach, Journal of Advanced Manufacturing Technology (JAMT), 2017, 11, 1.

[16] M. Ibrahim, M. A. Abdullah, F. Mohamed Jamil, M. H. Harun and F. Ahmad, Verification of Commercial Vehicle Ride Dynamics, Proceedings of Innovative Research and Industrial Dialogue 16, 2017, 185-186.

[17] D. Schramm, M. Hiller and R. Bardini, Model of a Typical Complex Complete Vehicle, Vehicle Dynamics, Springer, Berlin, Heidelberg, 2018, 351-371.

[18] X. Zhou and P. Venhovens, Calibration of Vehicle Dynamics and Stability Control Model, International Journal of Vehicle Systems Modelling and Testing, 2016, 11, 4, 285-312.

[19] F. Mohamed Jamil, M. A. Abdullah, M. Ibrahim, M. H. Harun and W. Z. Wan Abdullah, The Dynamic Verification of Vehicle Roll Dynamic Models using Different Software's, Proceedings of Innovative Research and Industrial Dialogue 16, 2017, 135-136.

[20] A. Ravi and S. Palani, Research on Sensorless Control Strategies for Vehicle Stability using Fuzzy based EDC, International Journal of Engineering and Technology (IJET), ISSN 0975-4024, 2014, 6, 2, 1017-1025.

\section{AUTHORS PROFILE}

Ahmed Esmael Mohan received M.E. degree in mechanical engineering from UTeM Malaysia. He is working in as an assistant lecturer in the Department of techniques engineering pumps at Al-Mussaib Technical college, Al-Furat Al-Awsat Technical university,Babylon, Iraq.

Dr. Mohd Azman Abdullah was awarded Doctor in Engineering (Dr. Eng.) from Tokyo University of Agriculture \& Technology in Mechanical Systems Engineering in 2011. His research fields are vehicle dynamics, railway vehicle dynamics and technology, vehicle control system, autonomous vehicle, multi-body dynamics and energy regeneration. He got his Master of Science (M. Sc.) in Automotive \& Motorsport Engineering in 2005 from Brunel University, United Kingdom. He is now an associate professor at the Department of Automotive, Faculty of Mechanical Engineering, UTeM, Malaysia and Charted Engineer (CEng) of the Engineering Council, UK through The Institution of Engineering and Technology (IET), UK. Currently, he is doing industrial attachment at the Rolling Stock Department, ERL Maintenance Support Sdn. Bhd (EMAS). His project with the high speed railway industry such as E-MAS is involving improvement in maintenance procedure. He has authored and co-authored over 100 referred journal and conference technical papers. In engineering education he and his team have published few modules and book chapters' including Vehicle Dynamics, Vehicle System Modeling \& Simulation, Vehicle Control System, Vehicle Dynamics \& Experimentation, Measurement \& Instrumentation and Vehicle Dynamics Modeling \& Simulation for internal use. Since 2012, he has actively served as committee, session chair and reviewer for over 20 international conferences. He is also a research fellow at the Centre for Advanced Research on Energy (CARe), UTeM. 